\title{
HPA axis and vagus nervous function are involved in impaired insulin secretion of MSG-obese rats
}

\author{
Rosiane A Miranda1,2,*, Rosana Torrezan3,*, Júlio C de Oliveira4, Luiz F Barella5, \\ Claudinéia C da Silva Franco1, Patrícia C Lisboa6, Egberto G Moura6 and \\ Paulo C F Mathias ${ }^{1}$
}

\author{
'Department of Biotechnology, Genetics and Cell Biology, State University of Maringá, Maringá, Brazil \\ ${ }^{2}$ Carlos Chagas Filho Biophysics Institute, Federal University of Rio de Janeiro, Rio de Janeiro, Brazil \\ ${ }^{3}$ Department of Physiological Sciences, State University of Maringá, Maringá, Brazil \\ ${ }^{4}$ Institute of Health Sciences, Federal University of Mato Grosso, Sinop, Brazil \\ ${ }^{5}$ Molecular Signalling Section, Laboratory of Bioorganic Chemistry, National Institute of Diabetes and \\ Digestive and Kidney Diseases, National Institutes of Health, Bethesda, MD, USA \\ ${ }^{6}$ Department of Physiological Sciences, Roberto Alcântara Gomes Biology Institute, State University of \\ Rio de Janeiro, Rio de Janeiro, Brazil \\ *(R A Miranda and R Torrezan contributed equally to this work)
}
Correspondence should be addressed to P C F Mathias Email
pmathias@uem.br

\begin{abstract}
Neuroendocrine dysfunctions such as the hyperactivity of the vagus nerve and hypothalamus-pituitary-adrenal (HPA) axis greatly contribute to obesity and hyperinsulinemia; however, little is known about these dysfunctions in the pancreatic $\beta$-cells of obese individuals. We used a hypothalamic-obesity model obtained by neonatal treatment with monosodium L-glutamate (MSG) to induce obesity. To assess the role of the HPA axis and vagal tonus in the genesis of hypercorticosteronemia and hyperinsulinemia in an adult MSG-obese rat model, bilateral adrenalectomy (ADX) and subdiaphragmatic vagotomy (VAG) alone or combined surgeries (ADX-VAG) were performed. To study glucose-induced insulin secretion (GIIS) and the cholinergic insulinotropic process, pancreatic islets were incubated with different glucose concentrations with or without oxotremorine- $M$, a selective agonist of the $M_{3}$ muscarinic acetylcholine receptor $\left(M_{3} A C h R\right)$ subtype. Protein expression of $M_{3} A C h R$ in pancreatic islets, corticosteronemia, and vagus nerve activity was also evaluated. Surgeries reduced $80 \%$ of the body weight gain. Fasting glucose and insulin were reduced both by ADX and ADX-VAG, whereas VAG was only associated with hyperglycemia. The serum insulin post-glucose stimulation was lower in all animals that underwent an operation. Vagal activity was decreased by $50 \%$ in ADX rats. In the highest glucose concentration, both surgeries reduced GIIS by $50 \%$, whereas ADX-VAG decreased by $70 \%$. Additionally, $M_{3} A C h R$ activity was recovered by the individual surgeries. $M_{3} A C h R$ protein expression was reduced by ADX. Both the adrenal gland and vagus nerve contribute to the hyperinsulinemia in the MSG model, although adrenal is more crucial as it appears to modulate parasympathetic activity and $M_{3} A C h R$ expression in obesity.
\end{abstract}

Journal of Endocrinology (2016) 230, 27-38
๑ 2016 Society for Endocrinology Printed in Great Britain
Published by Bioscientifica Ltd 


\section{Introduction}

Metabolic derangements, especially during early life, are the major etiology of chronic metabolic diseases worldwide. Obesity that is associated with cardiovascular and type 2 diabetes causes a high incidence of comorbidities and death (Kelly et al. 2008). The origins of obesity and the role of the pancreatic $\beta$-cell as a hallmark of metabolism malfunction during the onset of obesity are not clear. Glucose homeostasis imbalance has a tight association with $\beta$-cell malfunction, producing hyperinsulinemia during fasting and feeding states (Shafrir 1996).

Why is glucose-induced insulin secretion upregulated in obese human beings and experimental animal models? Several hypotheses have been proposed. One hypothesis is largely debatable: tissue insulin resistance provokes the oversecretion of insulin by $\beta$-cells (Grassiolli et al. 2006). Hyperglycemia supervenes on increased insulin resistance and a lack of consequent insulin release increases, which cause a toxic effect on $\beta$-cell function, leading to a vicious cycle (Solomon et al. 2012). This effect, known as glucotoxicity, may itself disrupt glucose signal transduction in $\beta$-cells to stimulate insulin release (Bensellam et al. 2012). Moreover, other secretagogues are also crucial to increase plasma insulin. Pancreatic $\beta$-cells receive many neural terminals, including the autonomic nervous system (ANS) with their parasympathetic (PNS) and sympathetic (SNS) branches, which release acetylcholine (ACh) and noradrenaline (NA), respectively. Although ACh potentiates a glucose insulinotropic effect, NA blocks this effect (Campfield \& Smith 1983). Cholinergic transduction in pancreatic $\beta$-cells mostly involves cholinergic muscarinic receptors (MAChR), which are constituted by four subtypes: $\mathrm{M}_{1}$, $\mathrm{M}_{2}, \mathrm{M}_{3}$, and $\mathrm{M}_{4}$. The cholinergic muscarinic insulinotropic effect lies mainly in the $\mathrm{M}_{3}$ subtype of MAChR ( $\left.\mathrm{M}_{3} \mathrm{AChR}\right)$ (Boschero et al. 1995).

Studies have suggested that in obese human beings and animals, the ANS is imbalanced, showing high vagal activity (Weyer et al. 2001). In addition, hyperinsulinemia has been observed in obese individuals and is associated with the hyperactivity of the PNS by releasing ACh. Regarding this matter, subdiaphragmatic vagotomy (VAG) has been performed to attenuate the hyperinsulinemia in monosodium L-glutamate (MSG)-treated rats and other obese models such as Wistar fatty models (Yamatani et al. 1998, Balbo et al. 2000). The MSG rat is an interesting model that reconciles increased parasympathetic activity, hyperinsulinemia, and obesity, among other components of the metabolic syndrome, mimicking the disorders observed in obese individuals (Hirata et al. 1997, Dolnikoff et al. 2001, Karlen-Amarante et al. 2012).

Pancreatic islets from MSG-obese rats incubated with carbachol, a cholinergic muscarinic agonist, showed lower insulin secretion than those from lean rats, demonstrating a weak cholinergic response (Balbo et al. 2002); however, $M_{3} A C h R$ was shown to be highly expressed in the pancreatic islets from MSG-obese rats (Miranda et al. 2014).

However, in addition to PNS hyperactivity, dysfunction in the hypothalamus-pituitary-adrenal (HPA) axis is an important factor that contributes to metabolic syndrome (Wang 2005, Laborie et al. 2011). In fact, excessive blood levels of glucocorticoids have been associated with insulin resistance and visceral obesity (de Guia \& Herzig 2015).

Lean adult rats treated with dexamethasone displayed hyperinsulinemia associated with high protein expression of $M_{3} A C h R$ in the pancreatic islets (Angelini et al. 2010). Furthermore, ablation of the adrenal glands normalized the blood insulin levels of hypothalamic obese rats (Perello et al. 2003). Accordingly, the high activity of both the PNS and HPA axis is hypothesized to contribute to the disrupted regulation of insulin secretion in obesity. Thus, to test this hypothesis, we subjected the MSG-obese rat model to either vagotomy or adrenalectomy or to both surgeries to evaluate the contribution of the PNS and HPA axis for pancreatic $\beta$-cell dysfunction.

\section{Materials and methods}

\section{Animals and obesity}

All experiments were undertaken according to the norms established by the Brazilian Association for Animal Experimentation (COBEA) and were previously approved by the Ethical Conduct Committee on Animal Use in Experimentation (protocol number 147/2012).

Neonate male Wistar rats were subcutaneously injected during the first 5 days of life with MSG at a dose of $4 \mathrm{~g} / \mathrm{kg}$ of body weight (BW) (Olney 1969, Hirata et al. 1997). Control animals received equimolar saline solution. All animals were weaned at 21 days of age. The animals were housed under controlled conditions in a $12 \mathrm{~h}$ light:12 $\mathrm{h}$ darkness cycle, with the lights switched on at 07:00-19:00 $\mathrm{h}$ and temperature at $21 \pm 2^{\circ} \mathrm{C}$. Water and standard rodent chow (Nuvital, Curitiba, Brazil) were supplied ad libitum. Only males were used in the experimental protocols. MSG rats that reached at least a $2.5 \%$ increase in the Lee index compared with those treated with saline solution were chosen.

Published by Bioscientifica Ltd. 
At 90 days of age, some of the rats from both groups, control and MSG, were used to evaluate body composition and metabolic parameters. The rats were anesthetized and killed to evaluate biometric and biochemical parameters to characterize the obesity induced by MSG. Other rats of the MSG group, randomly chosen, were submitted to bilateral subdiaphragmatic vagotomy (VAG), $n=20$, or to bilateral adrenalectomy (ADX), $n=30$, or both surgeries (ADX-VAG), $n=20$, whereas another batch of MSG rats were false operated (sham), $n=26$. All the rats that underwent the surgery procedures were kept in isolated cages during surgery rehabilitation for a period of 10 days. After the surgeries, 20\% of death was recorded to the adrenalectomized and/or vagotomized rats and 30\% to those submitted to both operations.

BW gain was evaluated by subtracting the weight of the animals 10 days after surgery to the weight before the surgery, and the food consumption was measured by weighing the remaining food, subtracting that amount from the ration offered to the animals the day before, and the values were expressed relative to $100 \mathrm{~g}$ of BW.

At 90 days of age, control and/or MSG rats that did not undergo an operation $(n=12)$, and all rats at 100 days of age (operated or sham-operated under anesthesia, $45 \mathrm{mg} / \mathrm{kg} / \mathrm{BW}$ thiopental) were killed by cervical dislocation. Then, the visceral fat pads were removed, washed, and weighed, and Lee index (BW (g) $)^{1 / 3} /$ nasal-anal length $(\mathrm{cm}) \times 100)$, which is employed as a predictor of obesity in MSG rodents (Bernardis \& Patterson 1968), was calculated. Blood samples were collected to measure glucose and hormone concentrations, including insulin, leptin, and corticosterone concentrations.

\section{Adrenalectomy}

Under anesthesia using thiopental ( $45 \mathrm{mg} / \mathrm{kg}$ BW i.p.), MSG rats at 90 days of age underwent bilateral ADX. The surgery was performed using a dorsal approach. ShamADX was performed using the same approach, with only localization of the adrenals, leaving the glands intact. $\mathrm{ADX}$ rats were maintained on $0.9 \% \mathrm{NaCl}$ to correct the aldosterone insufficiency throughout the 10 days following the operation (Su et al. 2015).

\section{Vagotomy}

Vagotomy and sham surgeries were performed in MSG animals, both intact and in ADX rats. Rats at 90 days of age after $12 \mathrm{~h}$ of fasting were anesthetized with thiopental ( $45 \mathrm{mg} / \mathrm{kg}$ BW i.p.). After laparotomy, both the dorsal and subdiaphragmatic vagal trunks were identified from the esophagus and severed with the aid of a stereomicroscope (Balbo et al. 2007). In sham vagotomized rats, the vagus nerve was separated from the esophagus but was not cut. After surgery, on the 10th day and after a $12 \mathrm{~h}$ fasting, the animals were anesthetized with thiopental $(45 \mathrm{mg} / \mathrm{kg}$ BW i.p.) and killed by decapitation. Using stomach food retention as a characteristic of vagotomy, 100-day-old animals from all the groups were observed. After killing the animals, the abdomens were opened and the stomachs were removed by severing the esophagus at one end and the pyloric sphincter at the other. The stomach was weighed, and the ratio of stomach weight to total BW was calculated. A confidence interval of $99 \%$ was employed to calculate the mean ratio for controls, and its upper limit was used as rejection criterion for vagotomy effectiveness (Bernstein \& Goehler 1983, Balbo et al. 2002).

\section{Intravenous glucose tolerance test}

Under ketamine and xylazine anesthesia (3 and $0.6 \mathrm{mg} / 100 \mathrm{~g}$ of BW, respectively), a silicone cannula was implanted into the right jugular vein of MSG rats, either in operated or sham-operated rats at 100 days of age. The cannula was stabilized in the dorsal region of the neck. The cannula was previously treated with heparinized saline (50 IU heparin/mL of saline solution $(\mathrm{NaCl}, 0.9 \%)$ ) to avoid blood clots. After a $12 \mathrm{~h}$ fast (19:00-07:00 h) and without anesthesia, a glucose load $(1 \mathrm{~g} / \mathrm{kg} \mathrm{BW})$ was infused through the cannula. Blood samples $(350-400 \mu \mathrm{L})$ were collected immediately before the glucose load $(0 \mathrm{~min})$ and at 5, 15, 30, and $45 \mathrm{~min}$ after the load (De Oliveira et al. 2013). Plasma obtained from the blood samples was stored at $-20^{\circ} \mathrm{C}$ for subsequent determination of glucose and insulin concentrations.

\section{Intraperitoneal insulin tolerance test}

A batch of control and MSG rats had a cannula implanted into the right jugular vein as described above and were fasted for $6 \mathrm{~h}$ before an intraperitoneal insulin tolerance test (ipITT; $1 \mathrm{U} / \mathrm{kg}$ BW). As previously described, the same method of blood collection used in the intravenous glucose tolerance test (ivGTT) was used to perform the ipITT. The absorption rate of glucose by the tissue (rate constant for the disappearance of plasma glucose $\left(\mathrm{K}_{\mathrm{itt}}\right)$ ) was calculated using the formula $0.693 /\left(t_{1 / 2}\right)$, which was already described (Lundbaek 1962). The plasma glucose $t_{1 / 2}$ was calculated from the slope of the least squares 
analysis of the plasma glucose concentrations during the linear phase of the decline (De Souza et al. 2005).

\section{Pancreatic islet isolation}

Pancreatic islets were isolated from operated or shamoperated rats using a collagenase enzyme technique as previously described, with some adaptation (Gravena et al. 2002). At 100 days of age, after being anesthetized with $45 \mathrm{mg} / \mathrm{kg}$ BW thiopental, the rats were decapitated and the abdominal wall was cut open. Then, $8 \mathrm{~mL}$ of Hanks buffered saline solution (HBSS, (mmol/L): $\mathrm{NaCl}$, 136.9; $\mathrm{KCl}, \quad 5.4 ; \mathrm{MgSO}_{4} 7 \mathrm{H}_{2} \mathrm{O}, 0.81 ; \mathrm{Na}_{2} \mathrm{HPO}_{4}, 0.34$; $\mathrm{KH}_{2} \mathrm{PO}_{4}, 0.44 ; \mathrm{CaCl}_{2} 2 \mathrm{H}_{2} \mathrm{O}, 1.26$; $\mathrm{NaHCO}_{3}$, 4.16; glucose, 0.06; BSA, 15 , and $\left(\mathrm{O}_{2}, 95 \%+\mathrm{CO}_{2}, 5 \%\right.$ mixed $) / 10 \mathrm{~min}$, $\mathrm{pH} 7.4)$ containing collagenase type XI, $0.1 \%$ plus BSA, $5 \%$, and HEPES, $0.6 \%$ (Sigma-Aldrich) was injected into the common bile duct. The pancreas was swollen with the collagenase solution and was quickly excised and incubated in a glass beaker for 17-18 min. The suspension was then discharged, and the precipitated islets were washed three times with HBSS. The islets were collected with the aid of a stereomicroscope. At least three rats from three different litters were used for each experimental procedure of each group of animals.

\section{Insulin secretion stimulation}

To adapt isolated pancreatic islets to a baseline glucose concentration $(5.6 \mathrm{mmol} / \mathrm{L})$, the islets were pre-incubated for $60 \mathrm{~min}$ in $1 \mathrm{~mL}$ of normal Krebs-Ringer solution ((mmol/L): $\mathrm{NaCl}, 115 ; \mathrm{NaHCO}_{3}, 24 ; \mathrm{KCl}, 1.6 ; \mathrm{MgCl}_{6} \mathrm{H}_{2} \mathrm{O}$, $\left.1 ; \mathrm{CaCl}_{2} 2 \mathrm{H}_{2} \mathrm{O}, 1 ; \mathrm{BSA}, 15\right)$ and $\mathrm{pH} 7.4$ containing $5.6 \mathrm{mmol} / \mathrm{L}$ glucose. To study glucose-induced insulin secretion, after the pre-incubation, a batch of pancreatic islets were incubated for a further $60 \mathrm{~min}$ in Krebs-Ringer solution containing different glucose ((mmol/L): 5.6, 8.3, and 16.7) concentrations. Another batch of pancreatic islets were incubated for a further $60 \mathrm{~min}$ in Krebs-Ringer solution containing different glucose (basal, $5.6 \mathrm{mmol} / \mathrm{L}$ ) or (high $16.7 \mathrm{mmol} / \mathrm{L}$ ) concentrations in the presence or absence of a selective $\mathrm{M}_{3} \mathrm{AChR}$ agonist, oxotremorine-M $(1 \mathrm{mmol} / \mathrm{L})$, to evaluate the cholinergic muscarinic insulinotropic response.

\section{Western blot analyses}

Isolated pancreatic islet $\mathrm{M}_{3} \mathrm{AChR}$ content from 100-dayold MSG rats, either operated or sham-operated, was determined by immunoblotting. Three hundred islets of each experimental group were frozen at $-80^{\circ} \mathrm{C}$ in HBSS to posterior sonication (two times, $10 \mathrm{~s}$ pulses, Sonic Dismembrator Model 100, Thermo Fisher Scientific) in $300 \mu \mathrm{L}$ of lysis buffer ((mmol/L): HEPES, $50 ; \mathrm{MgCl}_{2}$, 1; EDTA, 10, and Triton $\mathrm{X}, 1 \%$ ) and centrifugation $\left(1120 \boldsymbol{g}, 4^{\circ} \mathrm{C} / 5 \mathrm{~min}\right)$. The supernatant was collected, $10 \mu \mathrm{L} / \mathrm{mL}$ of protease inhibitor cocktail (Roche) was added, and the total protein content was determined using the BCA Protein Assay Kit (Thermo Scientific) and a microplate reader (Multi-Mode Reader, FlexStation 3 Benchtop, Molecular Devices, Sunnyvale, CA, USA). The samples were treated with Laemmli sample buffer (glycerol, 20\%; $\beta$-mercaptoethanol, 10\%; 10\% SDS, 40\%; Tris, $0.5 \mathrm{~mol} / \mathrm{L}$, and $\mathrm{pH} 6.8,0.5 \%$; deionized water and bromophenol blue) and heated in a boiling water bath for 3 min (Laemmli 1970).

Forty micrograms of the total protein extracts from pancreatic islets were separated by the 10\% SDS-PAGE at $90 \mathrm{~V} / 120 \mathrm{~min}$. The proteins were then transferred from the gel to a nitrocellulose membrane (Trans-Blot SemiDry 15-min Electrophoretic Transfer Cell, Bio-Rad) and blocked with $5 \%$ of skimmed milk in Tris- $\mathrm{HCl}, 1 \mathrm{~mol} / \mathrm{L}$; $\mathrm{NaCl}, 5 \mathrm{~mol} / \mathrm{L}$, and Tween $20,0.05 \%$ at room temperature for 90 min while shaking. Then, the membrane was incubated overnight at $4^{\circ} \mathrm{C}$ with rabbit anti- $\mathrm{M}_{3} \mathrm{mAChR}$ polyclonal primary antibodies 1:1000 (Sigma-Aldrich) followed by peroxidase-conjugated anti-rabbit antibody 1:5000 diluted in Tris- $\mathrm{HCl}, 20 \mathrm{mmol} / \mathrm{L} ; \mathrm{NaCl}, 137 \mathrm{mmol} / \mathrm{L}$, and Tween 20, 0.05\%.

Immunoreactive proteins were visualized with ECL (GE Healthcare) and an imager (ImageQuant LAS 500, GE Healthcare). The bands were quantified by densitometry using Image 1.4 software (Wayne Rasband, National Institutes of Health, Bethesda, MD, USA). $\beta$-Actin protein content (Santa Cruz Biotechnology; diluted 1:1000 in Tris buffered saline) was utilized for normalization. Representative western blot images were originated from the same membrane.

\section{Electrical activity of vagus nervous}

MSG rats that were not vagotomized, either ADX or sham, were anesthetized with thiopental ( $45 \mathrm{mg} / \mathrm{kg}$ BW i.p.) after a 12-h fast. A longitudinal surgical incision was made on the anterior cervical region. Under a dissection microscope, the nerve bundle of the left vagus superior branch was severed from the carotid artery close to the trachea. The nerve trunk was pulled with a fine cotton suture line, 
and a pair of recording silver electrodes $(0.6 \mathrm{~mm}$ in diameter) was placed under the nerve. The nerve was covered with silicone oil to prevent dehydration. The electrode was connected to an electronic device (BioAmplificator, Insight, Ribeirão Preto, SP, Brazil) that amplified the electrical signal up to 10,000 times. To exclude the low and high frequencies, recordings from 1 to $80 \mathrm{kHz}$ were filtered. The neural signal output was acquired by an Insight interface (Insight, Ribeirão Preto, SP, Brazil), viewed online and stored by a personal computer running software developed by Insight.

During data acquisition, the animals remained in a Faraday cage to avoid any electromagnetic noise. The nerve activity was analyzed by the number of spikes over the course of $5 \mathrm{~s}$. The spikes were characterized by a depolarization that surpassed $0 \mathrm{mV}$. After a stabilization of the signal over the course of $2 \mathrm{~min}, 20$ record frames of $15 \mathrm{~s}$ were randomly chosen from each animal for spike counting. The average number of spikes was used to calculate the rate of nerve firing for each rat (Gomes et al. 2013).

\section{Plasmatic parameters}

Immediately after the killing the overnight fasted rats from all groups, blood samples were processed to obtain plasma, which was stored in $-80^{\circ} \mathrm{C}$ until determination of the corticosterone concentration using an RIA kit (ICN Biomedicals, Inc., Aurora, OH, USA). The assay sensitivity was $50 \mathrm{ng} / \mathrm{mL}$, and intra-assay variation was $7 \%$. The leptin levels were determined using an ELISA kit (Enzo Life Sciences, Plymouth Meeting, PA, USA). The intra- and inter-assay coefficients of variation were 5.9 and $7.2 \%$, respectively, for leptin.

The glucose concentration was measured by the glucose oxidase method (Trinder 1969) using a commercial kit (Gold Analisa Diagnóstica, Belo Horizonte, MG, Brazil).

The insulin resistance index (IRI) was calculated by the product of fasting insulin $(\mu \mathrm{IU} / \mathrm{mL}) \times$ fasting glucose (mmol/L) (Fagundes et al. 2009, Lima Nda et al. 2011, Li et al. 2012).

\section{Insulin level analyses}

The insulin level from the plasma and pancreatic islet incubation samples was determined by RIA (Scott et al. 1981). Human insulin was used as a standard along with an antirat insulin antibody (Sigma-Aldrich) and 125I-labeled recombinant human insulin (PerkinElmer). The intra- and inter-assay coefficients of variation were
12.2 and $9.8 \%$, respectively, for insulin. The detection limit for the insulin level was $1.033 \mathrm{pmol} / \mathrm{L}$. A gamma counter (Wizard ${ }^{2}$ Automatic Gamma Counter, TM-2470, PerkinElmer) was used to measure the radioactivity.

Unless cited, compounds and drugs used in this study were purchased from Sigma-Aldrich.

\section{Statistical analysis}

Results are shown as mean \pm s.E.M. Data were submitted to Student's $t$-test or one-way ANOVA, followed by Tukey's post-test analysis, when appropriate, comparing experimental and control groups. $P$ values $<0.05$ were considered to be statistically significant. Tests were performed using GraphPad Prism version 6.0 for Windows (GraphPad Software).

\section{Results}

Neonatal treatment with MSG induced many hallmarks of the metabolic syndrome. MSG rats presented less BW, body length, and food intake, 24\%; 14\% $(P<0.01)$ and $17 \%(P<0.0001)$, respectively, compared with control animals (Table 1). MSG rats also presented a $5 \%$ increase in the Lee index $(P<0.05)$ and a 1.3 -fold increase in visceral fat pad mass $(P<0.0001)$. Although normoglycemic, MSG rats presented a two-fold increase in insulin levels $(P<0.0001)$ compared with control rats. The leptin and corticosterone levels increased by 14.5 -fold and 3 -fold $(P<0.001)$, respectively. In the peripheral tissue, $\mathrm{K}_{\mathrm{itt}}$ was reduced by $76 \%$ in MSG rats $(P<0.0001)$.

Although 100-day-old sham rats gained $3 \mathrm{~g}$ compared with their BW at 90 days of age $(P<0.05)$, animals

Table 1 Effect of neonatal MSG treatment on biometric and biochemical parameters in adult rats.

\begin{tabular}{l} 
Parameters \\
\hline Body weight $(\mathrm{g})$ \\
Body length $(\mathrm{cm})$ \\
Lee index \\
Food intake $(\mathrm{g} / 100 \mathrm{~g} \mathrm{BW})$ \\
Visceral fat pad $(\mathrm{g} / 100 \mathrm{~g} \mathrm{BW})$ \\
Fasting glucose $(\mathrm{mg} / \mathrm{dL})$ \\
Fasting insulin $(\mathrm{ng} / \mathrm{mL})$ \\
Fasting corticosterone $(\mathrm{ng} / \mathrm{mL})$ \\
Fasting leptin $(\mathrm{ng} / \mathrm{mL})$ \\
$\mathrm{K}_{\text {itt }}(\% / \mathrm{min})$
\end{tabular}

\begin{tabular}{ccc}
\hline \multicolumn{1}{c}{ Control } & & MSG \\
\cline { 1 - 1 } $371.0 \pm 6.5$ & & $284.1 \pm 7.2 * *$ \\
$22.4 \pm 0.3$ & & $19.3 \pm 0.3^{* *}$ \\
$31.5 \pm 0.3$ & & $33.4 \pm 0.4^{*}$ \\
$7.48 \pm 0.09$ & & $6.21 \pm 0.15^{* * *}$ \\
$0.83 \pm 0.05$ & & $1.99 \pm 0.10^{* * *}$ \\
$101.9 \pm 1.95$ & & $106.3 \pm 3.48^{\text {NS }}$ \\
$0.51 \pm 0.02$ & & $1.06 \pm 0.07^{* * *}$ \\
$275.5 \pm 81.7$ & & $612.0 \pm 74.1 * *$ \\
$1.57 \pm 0.70$ & & $22.80 \pm 0.59 * *$ \\
$2.99 \pm 0.17$ & & $0.71 \pm 0.21^{* * *}$ \\
\hline
\end{tabular}

The data represent the mean \pm S.E.M. obtained from 12 rats per experimental group. The symbols represent significant differences by Student's $t$-test, ${ }^{*} P<0.05,{ }^{*} P<0.01, * * * P<0.0001$, NS, not significant.
() 2016 Society for Endocrinology Printed in Great Britain 
A
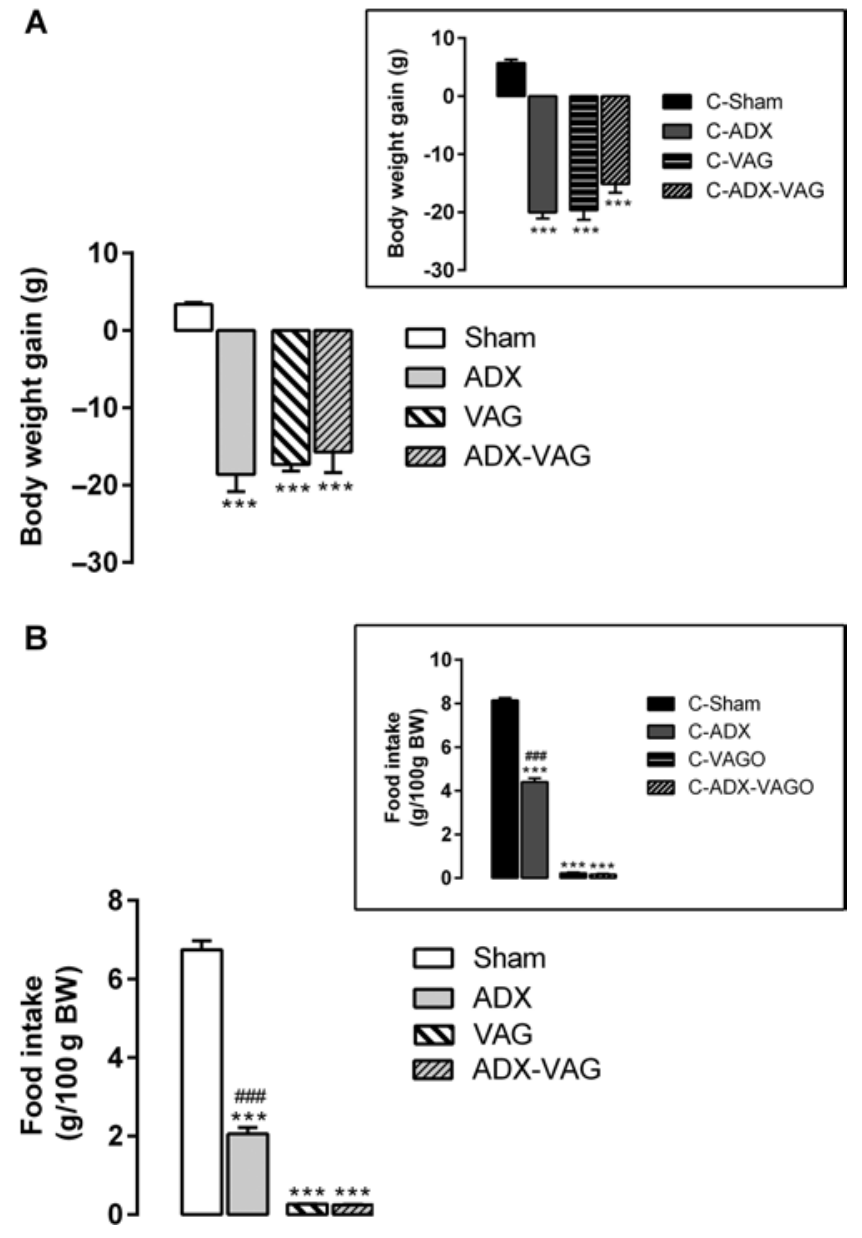

Figure 1

Effect of adrenalectomy, vagotomy, or both surgeries on body weight (A) and food intake (B) in control and MSG rats, 10 days after the surgery. The values are the mean \pm S.E.M. ( $n=8-12$ per group) by one-way ANOVA. $* * * P<0.0001$ significantly different from the sham, $\# \# P<0.0001$ significantly different from the ADX-VAG.

that underwent the surgeries, adrenalectomy, vagotomy, and both, displayed an approximately $18 \mathrm{~g}$ reduction of BW compared with sham rats $(P<0.0001)$, without any significant difference among the operated animals, as shown in Fig. 1A. Adrenalectomy induced a $69 \%$ reduction in food intake $(P<0.0001)$, and vagotomy caused a 96\% $(P<0.0001)$ decrease alone and when associated with adrenalectomy compared with sham rats (Fig. 1B).
The control operated animals displayed the same features of the MSG operated rats in both BW gain and food intake, as shown in insets in Fig. 1A and B.

The fasting glucose blood levels are shown in Fig. 2A. Compared with the values of fasting glycemia observed in sham rats, adrenalectomy caused a $25 \%$ decrease $(P<0.0001)$, whereas vagotomy provoked a $26 \%$ increase $(P<0.001)$; however, adrenalectomy associated with vagotomy caused a $19 \%$ decrease in fasting glycemia $(P<0.001)$ compared with sham rats.

As shown in Fig. 2B, fasting insulinemia was reduced by $88 \%$ after adrenalectomy $(P<0.0001)$ and by $84 \%$ $(P<0.0001)$ in both operations compared with sham rats. Vagotomy did not reduce insulinemia compared with sham rats. The IRI was decreased $92 \%$ by adrenalectomy $(P<0.0001)$ and by $86 \%(P<0.0001)$ in ADX-VAG, compared with sham rats (Fig. $2 \mathrm{C}$ ).

Although glycemia was unaltered during ivGTT among the MSG groups (Fig. 3A), the insulin level was reduced by $21 \%(P<0.001)$ upon adrenalectomy, $46 \%$ upon vagotomy $(P<0.001)$, and $53 \%$ upon both surgeries $(P<0.0001)$ (Fig. 3B).

Vagotomized rats showed 20\% less corticosterone than sham rats, but the difference was not statistically significant (Fig. 4). The levels of corticosterone in ADX and ADX-VAG rats were undetectable. Electrical vagus records are shown in Fig. 5; adrenalectomy provoked a reduction of $41 \%$ in vagus nervous activity $(P<0.0001)$ compared with sham rats.

In general, isolated pancreatic islets from sham rats displayed a curved dose-response to glucose, as shown in Fig. 6A. In addition, pancreatic islets from adrenalectomized and vagotomized rats increased their insulin release with an increase in the glucose concentration; however, the operations did not present the same profiles, with an increase only in the highest glucose concentration. In the same way, adrenalectomized rats showed a lower insulin release in comparison to sham-operated animals only in the highest glucose concentration. The other operated animals secreted less insulin than sham-operated rats when stimulated by different glucose concentrations.
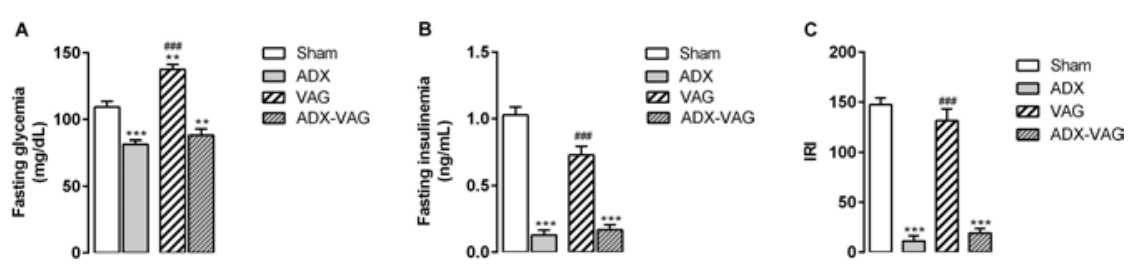

Figure 2

Effect of adrenalectomy, vagotomy, or both surgeries on the fasting glycemia (A), insulinemia (B), and IRI (C) in MSG rats, 10 days after the surgery. The values are the mean \pm S.E.M. $(n=8-12$ per group) by one-way ANOVA. $* * P<0.001$ and $* * * P<0.0001$

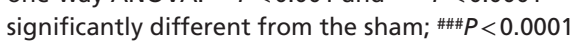
significantly different from the ADX-VAG. 

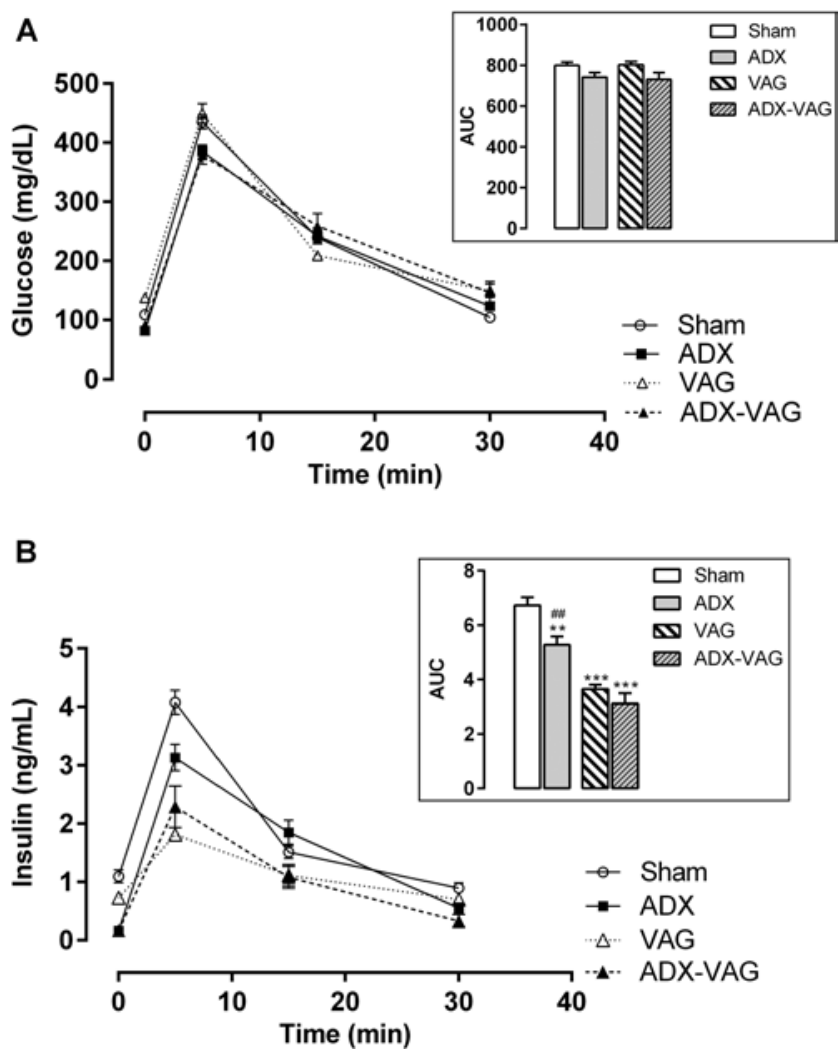

Figure 3

Effect of adrenalectomy, vagotomy, or both surgeries on the glycemia (A) and insulinemia (B) during ivGTT in MSG rats, 10 days after the surgery. The insets in each figure represent the respective areas-under-the-curve (AUC) of glycemia and insulinemia. Values are the mean \pm s.E.M. $(n=8-12$ per group) by one-way ANOVA. $* * P<0.001$ and $* * * P<0.0001$ significantly different from the sham; $\# P<0.001$ significantly different from ADX-VAG.

In the basal glucose concentration $(5.6 \mathrm{mmol} / \mathrm{L})$, the selective $\mathrm{M}_{3} \mathrm{AChR}$ agonist (oxotremorine-M) potentiates insulin secretion from sham, adrenalectomized rats (approximately $80 \% ; P<0.01$ ), vagotomized rats, and adrenalectomized and vagotomized rats $(50 \%, P<0.01)$, as shown in Fig. 6B. At the high glucose concentrations $(16.7 \mathrm{mmol} / \mathrm{L})$, the potentiation of glucose-induced insulin secretion by oxotremorine-M increased two-fold compared with insulin secretion induced by glucose only in sham rats, whereas this insulinotropic effect of oxotremorine-M increased four-fold in adrenalectomized as well as vagotomized rats $(P<0.001)$. No action of oxotremorine-M in the pancreatic islets from rats that were adrenalectomized and vagotomized was observed (Fig. 6B).

Protein expression of $\mathrm{M}_{3} \mathrm{AChR}$ from isolated pancreatic islets is shown in Fig. 7. Vagotomy did not cause changes in $\mathrm{M}_{3} \mathrm{AChR}$ expression compared with sham

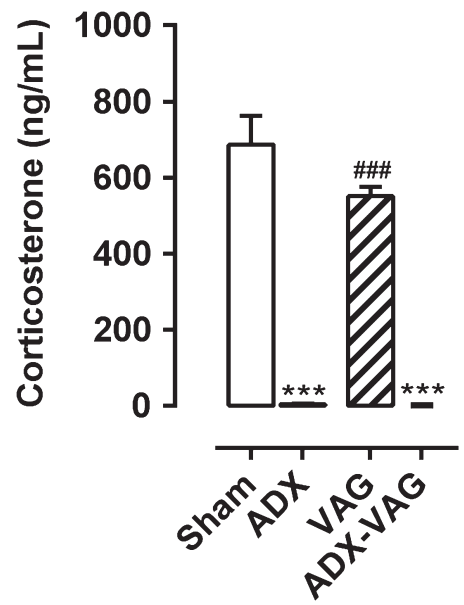

Figure 4

Effect of adrenalectomy, vagotomy, or both surgeries on the corticosterone blood levels from the MSG rats, 10 days after the surgery. The values are the mean \pm S.E.M. ( $n=8$ per group) by one-way ANOVA. $* * * P<0.0001$ significantly different from the sham; $\# \# P<0.001$ significantly different from ADX-VAG.

rats. Adrenalectomy and the combined surgeries caused a decrease in $\mathrm{M}_{3} \mathrm{AChR}$ expression (26 and $46 \%$, respectively, $P<0.05)$.

\section{Discussion}

Data from this study demonstrate that disruption of insulin secretion control in hypothalamic obesity is associated with impairment of the HPA axis and PNS, and each system contributes individually or in combination. The onset of obesity is associated with low sympathetic and high parasympathetic activities to sustain the accumulation of energy sources, such as fat tissue, decreasing catabolism, and increasing anabolism. Regarding the BW of MSG rats, we observed that they were lighter than respective control animals, which was the characteristic phenotype of this model as described by Remke et al. (1988), Dolnikoff et al. (2001), and Schoelch et al. (2002). Although there were no overweight rats, the MSG-obese rats were found to have more fat pad stores as compared with control animals (Bernardis \& Patterson 1968, Bray \& York 1998), which was correlated with lower growth hormone (Bakke et al. 1978, Acs et al. 1982) and reduced basal metabolic rate (Arndt et al. 1991).

Vagotomy attenuates obesity from different origins (Bray \& York 1998). In this study, subdiaphragmatic VAG was able to reduce BW gain. Decreasing corticosterone levels by adrenalectomy in obese animals also attenuates 


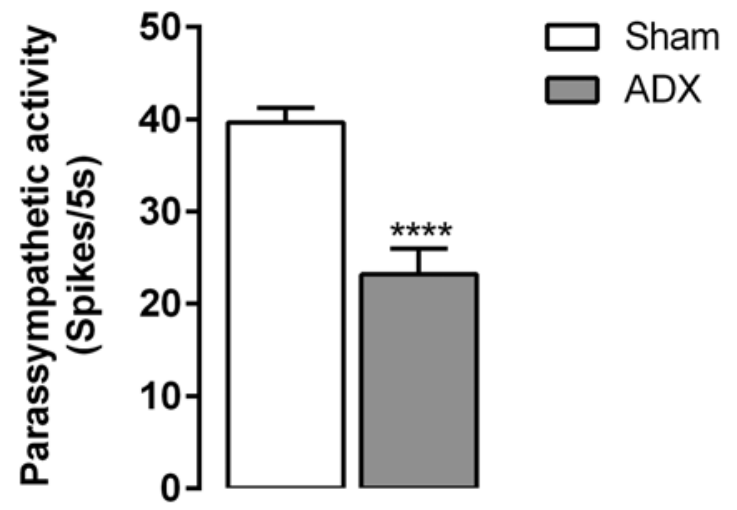

A
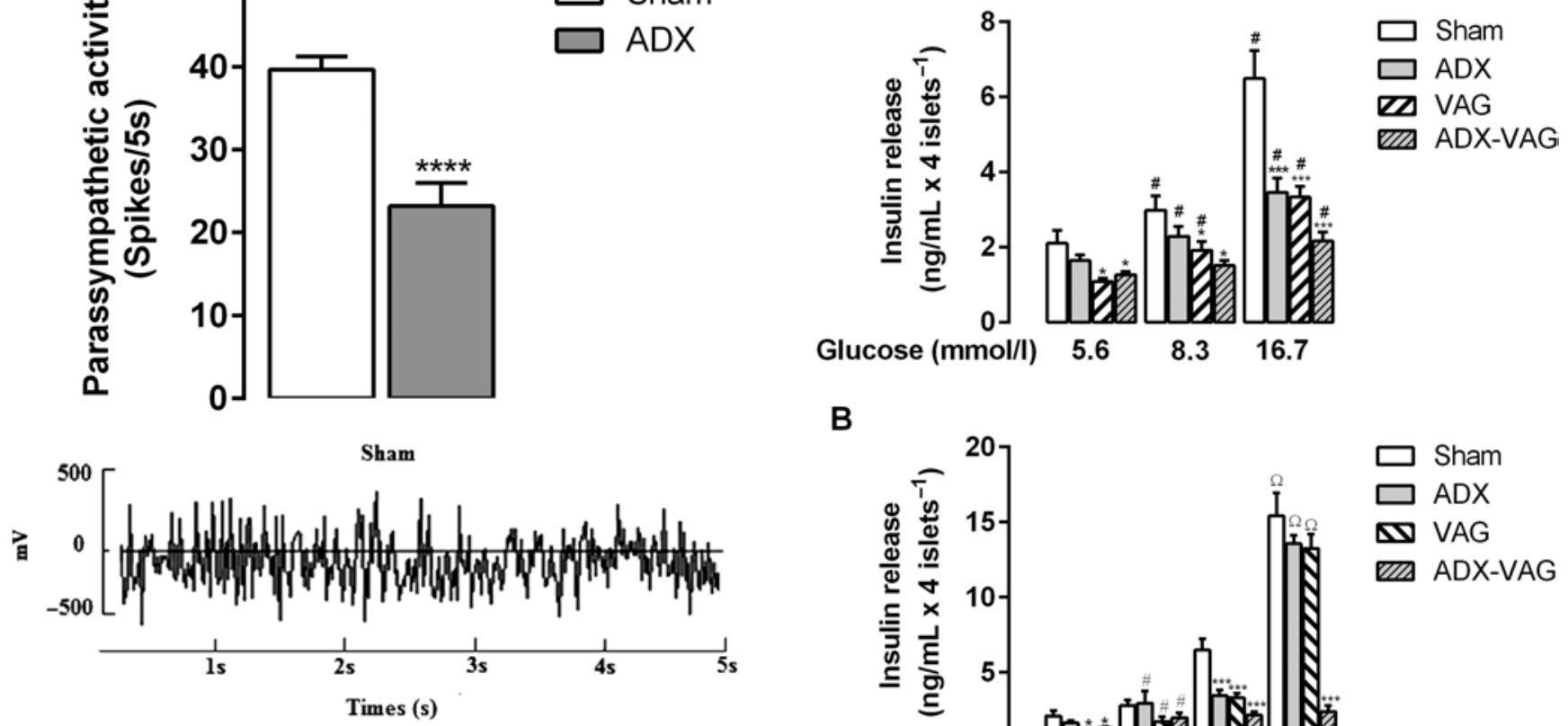

B
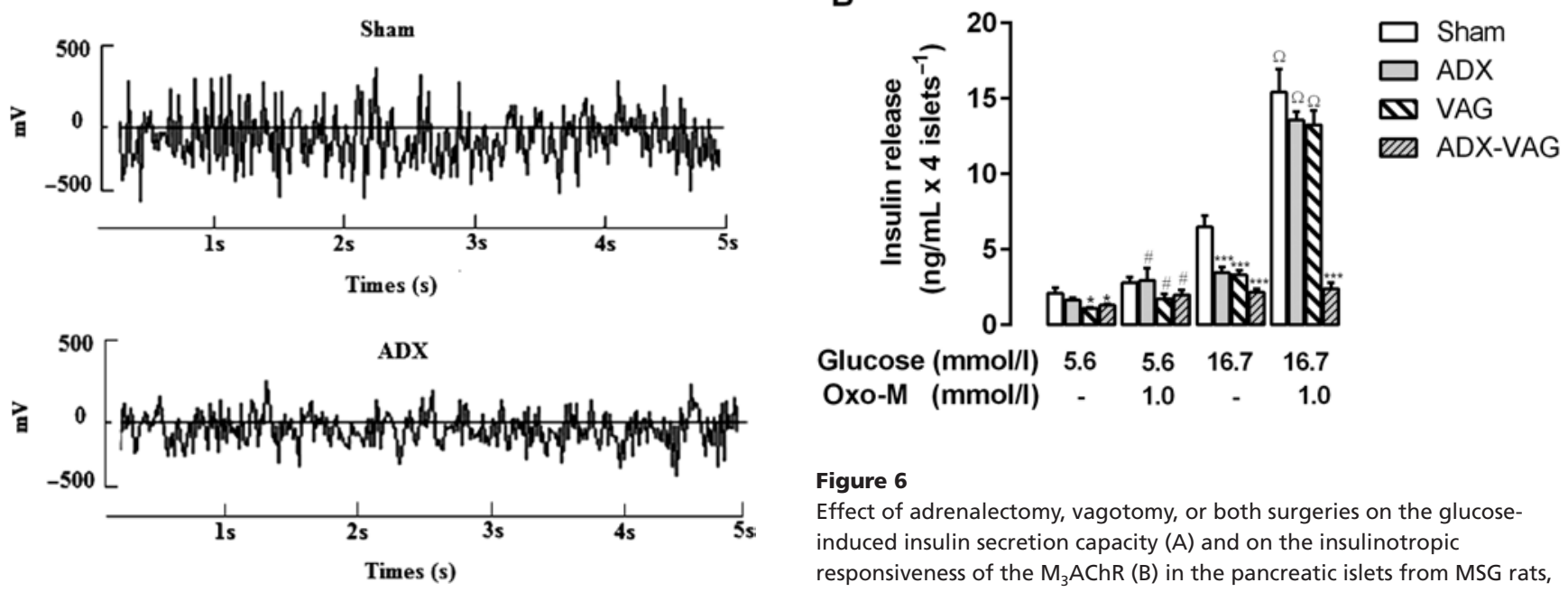

Figure 6

Effect of adrenalectomy, vagotomy, or both surgeries on the glucoseinduced insulin secretion capacity (A) and on the insulinotropic responsiveness of the $M_{3} A C h R(B)$ in the pancreatic islets from MSG rats, 10 days after the surgery. The values are mean \pm S.E.M. of insulin secreted by the isolated pancreatic islets obtained from six rats of three different litters for each experimental group. The symbols over the bars represent significant differences among the groups by one-way ANOVA, where in Fig. A $\left(^{*}\right)$ represents the comparison between each one of the group with sham group at each glucose concentration $\left({ }^{*} P<0.01\right.$ and $\left.* * * P<0.0001\right)$ and $(\#)$ represents the comparison between each one of the group at 8.3 or $16.7 \mathrm{mmol} / \mathrm{L}$ glucose concentrations with their counterpart at 5.6 $\mathrm{mmol} / \mathrm{L}(\# P<0.001)$. In Fig. $B,\left(^{*}\right)$ represents the comparison between each group with the sham group at each glucose and/or Oxo-M treatment $\left({ }^{*} P<0.01\right.$ and $\left.* * * P<0.0001\right)$, (\#) represents the comparison between each group treated with Oxo-M and their counterpart group without Oxo-M at $5.6 \mathrm{mmol} / \mathrm{L}$ glucose $(\# P<0.001)$, and $(\Omega)$ represents the comparison between each group treated with Oxo-M and their counterpart group without Oxo-M at $16.7 \mathrm{mmol} / \mathrm{L}$ glucose $(\Omega P<0.001)$. Oxo-M, oxotremorine-M.

Vagotomy or adrenalectomy reduced chow consumption in MSG rats; however, our findings suggest that interruption of vagus nervous activity plays a crucial role in food behavior compared with adrenal cortical activity. These data corroborate other previous studies in obese patients and animal obese models, which had reduced food intake when submitted to vagotomy (Cox et al. 2004, Yin et al. 2007, Zheng et al. 2009). Vagotomy prolongs gastric emptying and can affect the release of gastrointestinal hormones, such as ghrelin and glucagon-like peptide 1 (GLP1), which regulate orexigenic and anorexigenic hypothalamic neuropeptides. Vagotomy in obese rats decreased orexigenic signals by neuropeptide Y (NPY) in

the hypothalamus (Asakawa et al. 2001). Because MSG animals had increased corticosterone and this hormone increases appetite for palatable food, adrenalectomized animals had a great decrease in food intake. It is expected that after such surgeries, the animals markedly decrease their food intake and lose weight, but it seems that adrenalectomy is less traumatic to decrease food intake than vagotomy. However, without aldosterone, adrenalectomized animals lose more sodium, both via the kidney and gut. Moreover, gut sodium is important as a cotransporter for glucose and amino acid uptake.

Published by Bioscientifica Ltd. 


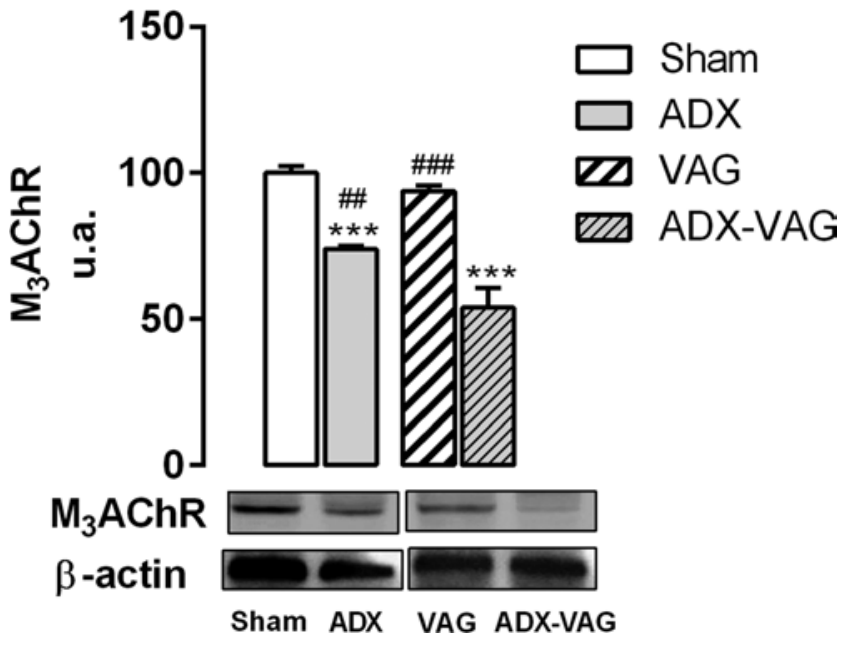

Figure 7 Effect of adrenalectomy, vagotomy, or both surgeries on $M_{3} A C h R$ protein expression in the pancreatic islets from six rats of three different litters per group for each experimental group, 10 days after the surgery. The values are the mean \pm S.E.M. by one-way ANOVA. $* * * P<0.0001$ significantly different from the sham; $\# P<0.001$ and $\# \# P<0.0001$ significantly different from ADX-VAG. Representative western blot images were carried out from the same membrane.

The reduction of body mass found in isolated surgeries is the same as that found in animals with both surgeries, showing that there is no additive effect of the combined surgeries. Glucocorticoids are able to increase fat mobilization as well as stimulate lipogenesis (Lee et al. 2014). Glucocorticoids in excess were found to decrease SNS activity (Grassi et al. 2001). This observation associated with high vagus nervous activity in MSG-obese rats suggests that imbalanced ANS activity contributes to high fat tissue accretion.

Chronic high corticosteroid administration is well known to cause insulin resistance and hyperinsulinemia (Yang et al. 2012). An elevated release of insulin is an effort of the pancreatic $\beta$-cell to maintain normal blood glucose (Litvinova et al. 2015). In this study, adrenalectomy abolished corticosterone serum levels with a parallel decrease in fasting glycemia and insulinemia. As expected, vagotomy provoked hyperglycemia, but surprisingly with no alteration in fasting insulinemia. In humans and many mammals, vagotomy provokes a fall in blood insulin levels. Surgery causes blunting of ACh release in pancreatic $\beta$-cell neuronal ends, which reduces the cholinergic response of glucose-induced insulin secretion (GIIS) (Henquin 2000). Glucocorticoids induce gluconeogenesis, which supports high blood glucose levels in humans and rodents submitted to chronic treatment with glucocorticoids (Rafacho et al. 2014). High HPA axis activity induces an enhancement of insulin secretion. Cutting of the vagus nerve and the effect on insulin release may be compensated by the chronic corticosterone-induced insulin secretion. Bernal-Mizrachi and co-workers showed that dexamethasone-treated rats displayed a disruption of the afferent vagus, glucose intolerance, and hypertension and the vagotomy was able to reverse these effects (Bernal-Mizrachi et al. 2007). They consider that glucocorticoid-induced glucose intolerance required intact vagal afferent fibers. Indeed, the complete mechanism of glucocorticoids action in stimulated vagus nerve is still not well understood (Bernal-Mizrachi et al. 2007). Although, it is important to highlight that intracerebroventricular (ICV) dexamethasone injections in vagotomized rats did not induce increased food intake, BW, or insulin resistance (Cusin et al. 2001). This central effect of glucocorticoids appears to be mediated, at least in part, by the PNS (Sainsbury et al. 1997).

In feeding conditions, using the ivGTT method, glycemia did not change, although insulin was lower after all surgeries. This result is suggestive of an increase in insulin sensitivity. Our data corroborate a previous report in which vagotomy improved insulin sensitivity in rat pups treated neonatally with MSG (Balbo et al. 2007). Importantly, glucocorticoids and vagal hypertonia suppression have different effects depending on fasting and feeding conditions. Decreasing corticosterone by adrenalectomy in fasting conditions appears to promote a normal response of insulin to glucose; however, in feeding conditions adrenalectomy seems to improve insulin sensitivity. This last effect is even more pronounced when vagotomy is performed in feeding conditions, whereas the insulin response was inappropriate in fasting conditions. The HPA axis and PNS show an influence on glycemic homeostasis, and together they may act synergistically on insulin secretion control.

As observed in vivo, both systems participate in the control of insulin levels, and isolated pancreatic islet function showed dependence for the two systems. Islets from obese rats presented a higher response to glucose than those from lean rats (Miranda et al. 2014). Vagotomy and adrenalectomy or both improved GIIS in isolated islets. Glucose is the main signal to stimulate $\beta$-cells to produce and secrete insulin. Herein, we suggest that hypercorticosteronemia associated with hyperactivity of vagus nerves contributes to functional changes in pancreatic $\beta$-cells in MSG-obese rats. In fact, as previously reported, hyperactivity of vagus nerves reduces apoptosis and increases proliferation in pancreatic $\beta$-cells (Medina et al. 2013), and excessive corticosteroids induce $\beta$-cell proliferation leading to insulin oversecretion (Rafacho et al. 2014).

$\mathrm{M}_{3} \mathrm{AChR}$ activity might also contribute to the glucose insulinotropic response in $\beta$-cells. Lean mice with $\mathrm{M}_{3} \mathrm{AChR}$ knockout present low insulin blood levels in fasting or fed

Published by Bioscientifica Ltd. 
conditions and a low glucose insulinotropic response in isolated pancreatic islets (Yamada et al. 2001). Nevertheless, pancreatic islets of mice with $\mathrm{M}_{3} \mathrm{AChR}$ overexpression show a high glucose insulinotropic response (Gautam et al. 2006). Indeed, this study shows that the glucose response was diminished in operated MSG rats, including both surgeries. These data can be associated with the decrease of $\mathrm{M}_{3} \mathrm{AChR}$ protein expression also observed in operated animals, suggesting a mechanism involving $\mathrm{M}_{3} \mathrm{AChR}$ quantity and/ or transduction signal changes; however, independent of the mechanism, both systems might modulate $\beta$-cell function.

Vagotomy in MSG-obese rats increases the cholinergic insulinotropic response (Balbo et al. 2002), as was shown with a selective $M_{3} A C h R$ agonist, oxotremorine- $\mathrm{M}$, in this study. The cholinergic response was decreased in pancreatic islets isolated from MSGobese rats compared with lean rats; however, the protein expression of $\mathrm{M}_{3} \mathrm{AChR}$ was increased (Miranda et al. 2014). In the animals treated with dexamethasone, an enhancement of $\mathrm{M}_{3} \mathrm{AChR}$ in pancreatic islets was found (Angelini et al. 2010). In this study, adrenalectomy significantly reduced the protein expression of $\mathrm{M}_{3} \mathrm{AChR}$ in the islets, whereas vagotomy alone did not show a statistical change. When adrenalectomy was combined with vagotomy, the decrease in $\mathrm{M}_{3} \mathrm{AChR}$ protein expression was even higher. Thus, together the HPA axis and ANS play an important role in regulating insulin secretion through $\mathrm{M}_{3} \mathrm{AChR}$.

For the first time, we have demonstrated that upon reducing corticosterone blood levels by adrenalectomy in MSG-obese rats, glucose homeostasis was improved as was pancreatic function by inhibiting insulin oversecretion. High protein expression of $\mathrm{M}_{3} \mathrm{AChR}$ was recently registered (Miranda et al. 2014) as was high vagus nerve activity in the MSG-obesity model reported by our group (Balbo et al. 2002, Miranda et al. 2014). Adrenalectomy as observed in this study was able to reduce $\mathrm{M}_{3} \mathrm{AChR}$ levels in the islets and inhibit electrical vagal activity. These results indicate that enhanced activity of the HPA axis augments vagal activity, which also allows changes in the protein expression and function of $\mathrm{M}_{3} \mathrm{AChR}$ from pancreatic $\beta$-cells.

Both systems, the HPA axis and ANS, influence the GIIS process, which can include changes in $\mathrm{M}_{3} \mathrm{AChR}$. The results also provide evidence to reinforce that pancreatic $\beta$-cell $M_{3} A C h R$ might be a new therapeutic target for metabolic diseases.

Taken together, data in this study suggest a synergistic action of the HPA axis and PNS hyperactivity on pancreatic $\beta$-cell physiology in MSG-obese rats leading to insulin oversecretion, which allows these animals to develop obesity.

\section{Declaration of interest}

The authors declare that there is no conflict of interest that could be perceived as prejudicing the impartiality of the research reported.

\section{Funding}

This work was supported by the Brazilian Federal Foundation, Conselho Nacional de Desenvolvimento Científico e Tecnológico (CNPq) and Coordenação de Aperfeiçoamento de Pessoal de Nível Superior (CAPES).

\section{Author contribution statement}

$R$ A M, R T, and P C F M were responsible for the conception and design of the study. R T, R A M, J C O, L F B, and C C S F collected, analyzed, and interpreted the data. R A M, P C L, P C F M, and E G M drafted and/or critically reviewed the manuscript. All authors approved the final version of the manuscript, all persons designated as authors qualify for authorship, and all those who qualify for authorship have been listed.

\section{References}

Acs Z, Antoni FA \& Makara GB 1982 Corticoliberin and somatoliberin activity in the pituitary-stalk median-eminence of rats after neonatal treatment with monosodium glutamate. Journal of Endocrinology 93 239-245. (doi:10.1677/joe.0.0930239)

Angelini N, Rafacho A, Boschero AC \& Bosqueiro JR 2010 Involvement of the cholinergic pathway in glucocorticoid-induced hyperinsulinemia in rats. Diabetes Research and Clinical Practice 87 184-191. (doi:10.1016/j.diabres.2009.11.008)

Arndt T, Rehorek A \& Muller F 1991 Assessment of cold induced alterations in catecholamine turnover of lean and glutamate-treated obese rats. Experimental and Clinical Endocrinology 98 207-211. (doi:10.1055/s-0029-1211119)

Asakawa A, Inui A, Kaga T, Yuzuriha H, Nagata T, Ueno N, Makino S, Fujimiya M, Niijima A, Fujino MA, et al. 2001 Ghrelin is an appetitestimulatory signal from stomach with structural resemblance to motilin. Gastroenterology 120 337-345. (doi:10.1053/gast.2001.22158)

Bakke JL, Lawrence N, Bennett J, Robinson S \& Bowers CY 1978 Late endocrine effects of administering monosodium glutamate to neonatal rats. Neuroendocrinology 26 220-228. (doi:10.1159/000122829)

Balbo SL, Bonfleur ML, Carneiro EM, Amaral ME, Filiputti E \& Mathias PC 2002 Parasympathetic activity changes insulin response to glucose and neurotransmitters. Diabetes Metabolism 28 3S13-3S17.

Balbo SL, Grassiolli S, Ribeiro RA, Bonfleur ML, Gravena C, Brito Mdo N, Andreazzi AE, Mathias PC \& Torrezan R 2007 Fat storage is partially dependent on vagal activity and insulin secretion of hypothalamic obese rat. Endocrine 31 142-148. (doi:10.1007/ s12020-007-0021-z)

Balbo SL, Mathias PC, Bonfleur ML, Alves HF, Siroti FJ, Monteiro OG, Ribeiro FB \& Souza AC 2000 Vagotomy reduces obesity in MSGtreated rats. Research Communications in Molecular Pathology and Pharmacology 108 291-296.

Bensellam M, Duvillie B, Rybachuk G, Laybutt DR, Magnan C, Guiot Y, Pouyssegur J \& Jonas JC 2012 Glucose-induced O(2) consumption activates hypoxia inducible factors 1 and 2 in rat insulin-secreting pancreatic beta-cells. PLOS ONE 7 e29807. (doi:10.1371/journal. pone.0029807) 
Bernal-Mizrachi C, Xiaozhong L, Yin L, Knutsen RH, Howard MJ, Arends JJ, Desantis P, Coleman T \& Semenkovich CF 2007 An afferent vagal nerve pathway links hepatic PPARalpha activation to glucocorticoid-induced insulin resistance and hypertension. Cell Metabolism 5 91-102. (doi:10.1016/j.cmet.2006.12.010)

Bernardis LL \& Patterson BD 1968 Correlation between 'Lee index' and carcass fat content in weanling and adult female rats with hypothalamic lesions. Journal of Endocrinology 40 527-528. (doi:10.1677/joe.0.0400527)

Bernstein IL \& Goehler LE 1983 Vagotomy produces learned food aversions in the rat. Behavioral Neuroscience 97 585-594. (doi:10.1037/0735-7044.97.4.585)

Boschero AC, Szpak-Glasman M, Carneiro EM, Bordin S, Paul I, Rojas E \& Atwater I 1995 Oxotremorine-m potentiation of glucose-induced insulin release from rat islets involves M3 muscarinic receptors. American Journal of Physiology 268 E336-E342.

Bray GA \& York DA 1998 The MONA LISA hypothesis in the time of leptin. Recent Progress in Hormone Research 53 95-118.

Campfield LA \& Smith FJ 1983 Neural control of insulin interaction of norepinephrine and acetylcholine. American Journal of Physiology $\mathbf{2 4 4}$ R629-R634.

Chow JT, Thompson GB, Grant CS, Farley DR, Richards ML \& Young WF Jr 2008 Bilateral laparoscopic adrenalectomy for corticotrophindependent Cushing's a review of the Mayo Clinic experience. Clinical Endocrinology 68 513-519. (doi:10.1111/j.1365-2265.2007.03082.x)

Cox JE, Kelm GR, Meller ST, Spraggins DS \& Randich A 2004 Truncal and hepatic vagotomy reduce suppression of feeding by jejunal lipid infusions. Physiology \& Behavior 81 29-36. (doi:10.1016/j. physbeh.2003.12.012)

Cusin I, Rouru J \& Rohner-Jeanrenaud F 2001 Intracerebroventricular glucocorticoid infusion in normal induction of parasympatheticmediated obesity and insulin resistance. Obesity Research 9 401-406. (doi:10.1038/oby.2001.52)

Dallman MF, Akana SF, Pecoraro NC, Warne JP, la Fleur SE \& Foster MT 2007 Glucocorticoids, the etiology of obesity and the metabolic syndrome. Current Alzheimer Research 4 199-204. (doi:10.2174/15672 0507780362236)

de Guia RM \& Herzig S 2015 How do glucocorticoids regulate lipid metabolism? Advances in Experimental Medicine and Biology 872 127-144. (doi:10.1007/978-1-4939-2895-8)

De Oliveira JC, Ludemann Camargo R, Barella LF, Chaves Souto Branco R, Gravena C, Grassiolli S, Torrezan R \& Cezar De Freitas Mathias P 2013 Anesthetic-induced transient hyperglycemia and insulin resistance do not depend on the sympathoadrenal axis. Minerva Endocrinologica $\mathbf{3 8}$ 379-388.

De Souza CT, Araujo EP, Prada PO, Saad MJ, Boschero AC \& Velloso LA 2005 Short-term inhibition of peroxisome proliferator-activated receptor-gamma coactivator-1alpha expression reverses diet-induced diabetes mellitus and hepatic steatosis in mice. Diabetologia 48 1860-1871. (doi:10.1007/s00125-005-1866-4)

Dolnikoff M, Martin-Hidalgo A, Machado UF, Lima FB \& Herrera E 2001 Decreased lipolysis and enhanced glycerol and glucose utilization by adipose tissue prior to development of obesity in monosodium glutamate (MSG) treated-rats. International Journal of Obesity and Related Metabolic Disorders 25 426-433. (doi:10.1038/sj.ijo.0801517)

Fagundes AT, Moura EG, Passos MC, Santos-Silva AP, de Oliveira E, Trevenzoli IH, Casimiro-Lopes G, Nogueira-Neto JF \& Lisboa PC 2009 Temporal evaluation of body composition, glucose homeostasis and lipid profile of male rats programmed by maternal protein restriction during lactation. Hormone and Metabolic Research 41 866-873. (doi:10. 1055/s-0029-1233457)

Gautam D, Han SJ, Hamdan FF, Jeon J, Li B, Li JH, Cui Y, Mears D, Lu H, Deng C, et al. 2006 A critical role for beta cell M3 muscarinic acetylcholine receptors in regulating insulin release and blood glucose homeostasis in vivo. Cell Metabolism 3 449-461. (doi:10.1016/j. cmet.2006.04.009)
Gomes RM, Tofolo LP, Rinaldi W, Scomparin DX, Grassiolli S, Barella LF, de Oliveira JC, Branco RC, Agostinho AR, Ribeiro TA, et al. 2013 Moderate exercise restores pancreatic beta-cell function and autonomic nervous system activity in obese rats induced by high-fat diet. Cellular Physiology and Biochemistry 32 310-321. (doi:10.1159/000354439)

Grassi G, Seravalle G, Dell'Oro R, Turri C, Pasqualinotto L, Colombo M \& Mancia G 2001 Participation of the hypothalamus-hypophysis axis in the sympathetic activation of human obesity. Hypertension $\mathbf{3 8}$ 1316-1320. (doi:10.1161/hy1201.096117)

Grassiolli S, Bonfleur ML, Scomparin DX \& de Freitas Mathias PC 2006 Pancreatic islets from hypothalamic obese rats maintain K+ATP channel-dependent but not -independent pathways on glucoseinduced insulin release process. Endocrine 30 191-196. (doi:10.1385/ endo:30:2:191)

Gravena C, Mathias PC \& Ashcroft SJ 2002 Acute effects of fatty acids on insulin secretion from rat and human islets of Langerhans. Journal of Endocrinology 173 73-80. (doi:10.1677/joe.0.1730073)

Henquin JC 2000 Triggering and amplifying pathways of regulation of insulin secretion by glucose. Diabetes 49 1751-1760. (doi:10.2337/ diabetes.49.11.1751)

Hirata AE, Andrade IS, Vaskevicius P \& Dolnikoff MS 1997 Monosodium glutamate (MSG)-obese rats develop glucose intolerance and insulin resistance to peripheral glucose uptake. Brazilian Journal of Medical and Biological Research 30 671-674.

Karlen-Amarante M, da Cunha NV, de Andrade O, de Souza HC \& Martins-Pinge MC 2012 Altered baroreflex and autonomic modulation in monosodium glutamate-induced hyperadipose rats. Metabolism 61 1435-1442. (doi:10.1016/j.metabol.2012.03.005)

Kelly T, Yang W, Chen CS, Reynolds K \& He J 2008 Global burden of obesity in 2005 and projections to 2030. International Journal of Obesity 32 1431-1437. (doi:10.1038/ijo.2008.102)

Laborie C, Molendi-Coste O, Breton C, Montel V, Vandenbulcke F, Grumolato L, Anouar Y \& Vieau D 2011 Maternal perinatal undernutrition has long-term consequences on morphology, function and gene expression of the adrenal medulla in the adult male rat. Journal of Neuroendocrinology 23 711-724. (doi:10.1111/j.13652826.2011.02159.x)

Laemmli UK 1970 Cleavage of structural proteins during the assembly of the head of bacteriophage T4. Nature 227 680-685. (doi:10.1038/227680a0)

Lee MJ, Pramyothin P, Karastergiou K \& Fried SK 2014 Deconstructing the roles of glucocorticoids in adipose tissue biology and the development of central obesity. Biochimica et Biophysica Acta 1842 473-481. (doi:10.1016/j.bbadis.2013.05.029)

Li S, Tse IM \& Li ET 2012 Maternal green tea extract supplementation to rats fed a high-fat diet ameliorates insulin resistance in adult male offspring. Journal of Nutritional Biochemistry 23 1655-1660. (doi:10.1016/j.jnutbio.2011.11.008)

Lima Nda S, de Moura EG, Passos MC, Nogueira Neto FJ, Reis AM, de Oliveira E \& Lisboa PC 2011 Early weaning causes undernutrition for a short period and programmes some metabolic syndrome components and leptin resistance in adult rat offspring. British Journal of Nutrition 105 1405-1413. (doi:10.1017/S0007114510005064)

Litvinova LS, Kirienkova EV, Mazunin IO, Vasilenko MA \& Fattakhov NS 2015 [Insulin resistance pathogenesis in metabolic obesity]. Biomeditsinskaia Khimiia 61 70-82. (doi:10.18097/pbmc20156101070)

Lundbaek K 1962 Intravenous glucose tolerance as a tool in definition and diagnosis of diabetes mellitus. BMJ 1 1507-1513. (doi:10.1136/ bmj.1.5291.1507)

Medina A, Yamada S, Hara A, Hamamoto K \& Kojima I 2013 Involvement of the parasympathetic nervous system in the initiation of regeneration of pancreatic beta-cells. Endocrine Journal 60 687-696.

Miranda RA, Agostinho AR, Trevenzoli IH, Barella LF, Franco CC, Trombini AB, Malta A, Gravena C, Torrezan R, Mathias PC, et al. 2014 Insulin oversecretion in MSG-obese rats is related to alterations in 
cholinergic muscarinic receptor subtypes in pancreatic islets. Cellular Physiology and Biochemistry 33 1075-1086. (doi:10.1159/000358677)

Olney JW 1969 Brain lesions, obesity, and other disturbances in mice treated with monosodium glutamate. Science 164 719-721. (doi:10.1126/science.164.3880.719)

Perello M, Gaillard RC, Chisari A \& Spinedi E 2003 Adrenal enucleation in MSG-damaged hyperleptinemic male rats transiently restores adrenal sensitivity to leptin. Neuroendocrinology 78 176-184. (doi:10.1159/000072799)

Rafacho A, Ortsater H, Nadal A \& Quesada I 2014 Glucocorticoid treatment and endocrine pancreas implications for glucose homeostasis, insulin resistance and diabetes. Journal of Endocrinology 223 R49-R62. (doi:10.1530/JOE-14-0373)

Remke H, Wilsdorf A \& Muller F 1988 Development of hypothalamic obesity in growing rats. Experimental Pathology 33 223-232. (doi:10.1016/S0232-1513(88)80076-8)

Sainsbury A, Rohner-Jeanrenaud F, Cusin I, Zakrzewska KE, Halban PA, Gaillard RC \& Jeanrenaud B 1997 Chronic central neuropeptide Y infusion in normal status of the hypothalamo-pituitary-adrenal axis, and vagal mediation of hyperinsulinaemia. Diabetologia 401269 1277. (doi:10.1007/s001250050820)

Schoelch C, Hubschle T, Schmidt I \& Nuesslein-Hildesheim B 2002 MSG lesions decrease body mass of suckling-age rats by attenuating circadian decreases of energy expenditure. American Journal of Physiology: Endocrinology and Metabolism 283 E604-E611. (doi:10.1152/ajpendo.00439.2001)

Scott AM, Atwater I \& Rojas E 1981 A method for the simultaneous measurement of insulin release and B cell membrane potential in single mouse islets of Langerhans. Diabetologia 21 470-475.

Shafrir E 1996 Development and consequences of insulin lessons from animals with hyperinsulinaemia. Diabetes Metabolism 22 122-131.

Solomon TP, Knudsen SH, Karstoft K, Winding K, Holst JJ \& Pedersen BK 2012 Examining the effects of hyperglycemia on pancreatic endocrine function in evidence for in vivo glucotoxicity. Journal of Clinical Endocrinology and Metabolism 97 4682-4691. (doi:10.1210/jc.20122097)
Su Y, van der Spek R, Foppen E, Kwakkel J, Fliers E \& Kalsbeek A 2015 Effects of adrenalectomy on daily gene expression rhythms in the rat suprachiasmatic and paraventricular hypothalamic nuclei and in white adipose tissue. Chronobiology International 32 211-224. (doi:10.3 109/07420528.2014.963198)

Trinder P 1969 Determination of blood glucose using an oxidaseperoxidase system with a non-carcinogenic chromogen. Journal of Clinical Pathology 22 158-161. (doi:10.1136/jcp.22.2.158)

Wang M 2005 The role of glucocorticoid action in the pathophysiology of the metabolic syndrome. Nutrition \& Metabolism 23. (doi:10.1186/1743-7075-2-3)

Weyer C, Salbe AD, Lindsay RS, Pratley RE, Bogardus C \& Tataranni PA 2001 Exaggerated pancreatic polypeptide secretion in Pima Indians: can an increased parasympathetic drive to the pancreas contribute to hyperinsulinemia, obesity, and diabetes in humans? Metabolism 50 223-230. (doi:10.1053/meta.2001.20170)

Yamada M, Miyakawa T, Duttaroy A, Yamanaka A, Moriguchi T, Makita R, Ogawa M, Chou CJ, Xia B, Crawley JN, et al. 2001 Mice lacking the M3 muscarinic acetylcholine receptor are hypophagic and lean. Nature 410 207-212. (doi:10.1038/35065604)

Yamatani K, Ohnuma H, Niijima A, Igarashi M, Sugiyama K, Daimon M, Manaka H, Tominaga M \& Sasaki H 1998 Impaired vagus nervemediated control of insulin secretion in Wistar fatty rats. Metabolism 47 1167-1173. (doi:10.1016/S0026-0495(98)90318-3)

Yang GK, Fredholm BB, Kieffer TJ \& Kwok YN 2012 Improved blood glucose disposal and altered insulin secretion patterns in adenosine A(1) receptor knockout mice. American Journal of Physiology: Endocrinology and Metabolism 303 E180-E190. (doi:10.1152/ ajpendo.00050.2012)

Yin J, Ouyang H \& Chen JD 2007 Potential of intestinal electrical stimulation for obesity: a preliminary canine study. Obesity $\mathbf{1 5}$ 1133-1138. (doi:10.1038/oby.2007.615)

Zheng J, DiLorenzo DJ, McLaughlin L, Roberts AT \& Greenway FL 2009 Stimulation of sympathetic innervation in the upper gastrointestinal tract as a treatment for obesity. Medical Hypotheses $\mathbf{7 2}$ 706-710. (doi:10.1016/j.mehy.2008.12.046)

Received in final form 4 April 2016

Accepted 22 April 2016

Accepted Preprint published online 25 April 2016
C 2016 Society for Endocrinology Printed in Great Britain 